\title{
Morphology of the larvae, male genitalia and DNA sequences of Anopheles (Kerteszia) pholidotus (Diptera: Culicidae) from Colombia
}

\author{
Jesús Eduardo Escovar ${ }^{1,2} /{ }^{+}$, Ranulfo González ${ }^{3}$, Martha L Quiñones ${ }^{1}$, \\ Richard C Wilkerson ${ }^{4}$, Fredy Ruiz ${ }^{4}$, Bruce A Harrison ${ }^{5}$
}

\begin{abstract}
'Universidad Nacional de Colombia, Bogotá, Cundinamarca, Colombia ${ }^{2}$ Universidad de la Salle, Bogotá, Cundinamarca, Colombia ${ }^{3}$ Faculty of Natural and Exact Sciences, Universidad del Valle, Valle, Colombia ${ }^{4}$ Walter Reed Biosystematics Unit, Smithsonian Institution, Museum Support Center, Suitland, MD, USA ${ }^{5}$ College of Health and Human Sciences, Western Carolina University, Clemmons, NC, USA
\end{abstract}

Since 1984, Anopheles (Kerteszia) lepidotus has been considered a mosquito species that is involved in the transmission of malaria in Colombia, after having been incriminated as such with epidemiological evidence from a malaria outbreak in Cunday-Villarrica, Tolima. Subsequent morphological analyses of females captured in the same place and at the time of the outbreak showed that the species responsible for the transmission was not An. lepidotus, but rather Anopheles pholidotus. However, the associated morphological stages and DNA sequences of An. pholidotus from the foci of Cunday-Villarrica had not been analysed. Using samples that were caught recently from the outbreak region, the purpose of this study was to provide updated and additional information by analysing the morphology of female mosquitoes, the genitalia of male mosquitoes and fourth instar larvae of An. pholidotus, which was confirmed with DNA sequences of cytochrome oxidase I and rDNA internal transcribed spacer. A total of 1,596 adult females were collected in addition to 37 larval collections in bromeliads. Furthermore, 141 adult females, which were captured from the same area in the years 1981-1982, were analysed morphologically. Ninety-five DNA sequences were analysed for this study. Morphological and molecular analyses showed that the species present in this region corresponds to An. pholidotus. Given the absence of An. lepidotus, even in recent years, we consider that the species of mosquitoes that was previously incriminated as the malaria vector during the outbreak was indeed An. pholidotus, thus ending the controversy.

Key words: Kerteszia - Anopheles pholidotus - male genitalia - DNA sequences

Mosquito species of the subgenus Kerteszia are exclusively located in the Neotropical areas of Central and South America. Except for Chile and Uruguay, their distribution ranges from the south of Mexico to southern Brazil. This subgenus is also present in the Caribbean, Trinidad and Tobago (de Carvalho-Pinto \& Lourençode-Oliveira 2004) and both the Atlantic and Pacific coastal areas (Marrelli et al. 2007), with some species present at altitudes of more than $1,000 \mathrm{~m}$ above sea level (a.s.l.) (Cova-García 1961, Harbach \& Navarro 1996).

Kerteszia subgenus consists of species that have been incriminated as malaria vectors and are related to the emergence of malaria in thermal floors at altitudes of over 1,500 $\mathrm{m}$ a.s.l. Moreover, in the malaria-heavy coastal regions of South America and in the eastern slopes of the Venezuelan Andes, members of this subgenus seem to be the most important species involved in the transmission of malaria (Benítez et al. 2004, Montoya-Lerma et al. 2011). Similarly, the species of Kerteszia have been incriminated in the transmission of "malaria by bromeliads", which is typical of protected areas because the

doi: 10.1590/0074-0276130596

Financial support: COLCIENCIAS (110145921478)

+ Corresponding author: jeescobar@unisalle.edu.co

Received 26 December 2013

Accepted 8 April 2014 epiphytic bromeliads are the only breeding sites. This is why these plants have been associated with the occurrence of the disease (Ueno et al. 2007).

Five of the 12 species described for this subgenus (Zavortink 1973, Collucci \& Sallum 2003) have been incriminated as malaria vectors: Anopheles bellator (Forattini et al. 1999), Anopheles cruzii (de Carvalho-Pinto \& Lourenço-de-Oliveira 2004), Anopheles homunculus (RubioPalis \& Zimmerman 1997), Anopheles neivai (Carvajal et al. 1989, Gutierrez et al. 2008) and Anopheles lepidotus (Quiñones et al. 1984, Montoya-Lerma et al. 2011).

In Colombia, seven species of the subgenus have been reported, among which An. neivai and An. lepidotus are considered malaria vectors, while Anopheles boliviensis is considered a seasonal vector only (Quiñones et al. 1984, Montoya et al. 1994, Olano et al. 2001).

Since 1984, An. lepidotus has been considered, using epidemiological evidence (namely, mosquito density correlated with malaria cases; $98 \%$ of the Anopheles species found in the malaria focal area corresponded to this species), to be one of the species responsible for malaria transmission in Colombia, particularly in the focal area of Cunday-Villarrica, Department of Tolima. It has been suggested that An. lepidotus is part of a complex of species in which members of this complex are difficult to be differentiated morphologically. Specimens of Kerteszia from Ecuador and Venezuela have been analysed using molecular tools, thereby providing evidence for a complex of species: An. lepidotus could exist with Anopheles pholidotus and An. boliviensis in a complex of at least 
four or five different species (R Wilkerson, unpublished observations, Sallum et al. 2002).

González and Carrejo (2009), using observations of specimens of what was supposedly An. lepidotus, noted that the mosquito is very similar to An. pholidotus and both species were called An. boliviensis before Zavortink's (1973) descriptions. As a result, the holotype and paratype described by Komp (1937) as An. boliviensis is actually An. lepidotus. They also affirm that of the 204 Colombian specimens deposited at the University of California, Los Angeles and the National Museum of Natural History (NMNH) at the Smithsonian Institution collections and predetermined to be An. boliviensis as analysed by Zavortink (1973), 85\% corresponded to An. lepidotus. Similarly, González and Carrejo (2009), based on the analysis of male genitalia and larvae of four specimens from Cunday-Villarrica, suggested the possibility that $A n$. pholidotus occurred in this region. The importance of the above conclusion is that in Colombia, the region of Cunday-Villarrica is considered to be a focal area of malaria, where An. lepidotus had been incriminated as the possible vector for more than 25 years (Quiñones et al. 1984).

Recently, Harrison et al. (2012) resolved the problem of separating An. lepidotus from An. pholidotus females by re-describing both species and preparing a taxonomic key. These methods were used to differentiate females, the IV instar larvae, pupae and male genitalia of $A n$. lepidotus from other species of Kerteszia. They examined specimens of An. lepidotus from Colombia, Ecuador and Peru and female specimens of An. pholidotus from Bolivia, Colombia, Costa Rica, Ecuador and Venezuela. They agree with the preliminary results of Escobar et al. (2010), who stated that the primary vector in Tolima is $A n$. pholidotus and not An. Lepidotus, as had been reported since 1984 (Quiñones et al. 1984). Nevertheless, Harrison et al. (2012) only analysed 33 females of An. pholidotus captured between 1981-1983 in Tolima. Therefore, this conclusion was pending the analysis of the morphology of associated stages, the male genitalia and the inclusion of DNA sequences from samples of An. pholidotus that were recently obtained from the study area.

Since the controversy surrounding the identity of the vector in Tolima began more than 30 years ago, the aim of this study was to provide updated and additional information that was not presented by Harrison et al. (2012). This information includes the morphology of larvae, the male genitalia of An. pholidotus and their association with the DNA sequences of specimens that were recently collected in Colombia.

In this study, we analysed the morphological characteristics of 1,596 recently captured females, the chaetotaxy of IV instar larvae and the male genitalia of specimens of An. pholidotus from three localities in Tolima. Molecular analysis for gen cytochrome oxidase I (COI), internal transcribed spacer (ITS2) and sequencing was performed to verify the results obtained from the morphological information.

This study provides definitive morphological and molecular information supporting the conclusion that the malaria vector in Tolima is An. pholidotus and that it is actually the only malaria vector present in the area.

\section{MATERIALS AND METHODS}

Study site - The malaria focal area of Cunday-Villarrica is composed of the municipalities of Cunday, Villarrica, Dolores, Prado and Purificación ( $03^{\circ} 57^{\prime} \mathrm{N} 074^{\circ} 36^{\prime} \mathrm{W}$ ) (Fig. 1), which are situated on the western slopes of the eastern mountain chain and have an average temperature of $24^{\circ} \mathrm{C}$ and an annual rainfall of between 2,000-4,000 $\mathrm{mm}$. This area is approximately $100 \mathrm{Km}^{2}$ and is characterised by humid forests that have an abundance of epiphytes. This area has had stable malaria transmission for more than 25 years. Moreover, malaria cases reported in Tolima have been almost exclusively from that focal area.

Sampling strategy and adult mosquitoes - Collections of biological material were made between February 2009-June 2012. Adult females were captured using human landing collections inside and around houses and in the forest during periods of peak biting at various locations in the municipalities in this study. Captured females were individualised in vials and brought to the entomology laboratory of the National University of Colombia for preservation and taxonomic determination. Additionally, adult females of Kerteszia, which were collected between 1981-1983 in the same study area and belonged to the collection of the entomology laboratory of the Museum of Entomology, University of Valle, were analysed morphologically.

Entomological series - Mosquitoes in immature stages (larva and pupa) were captured directly from water at the base of bromeliads leaves by drawing out their

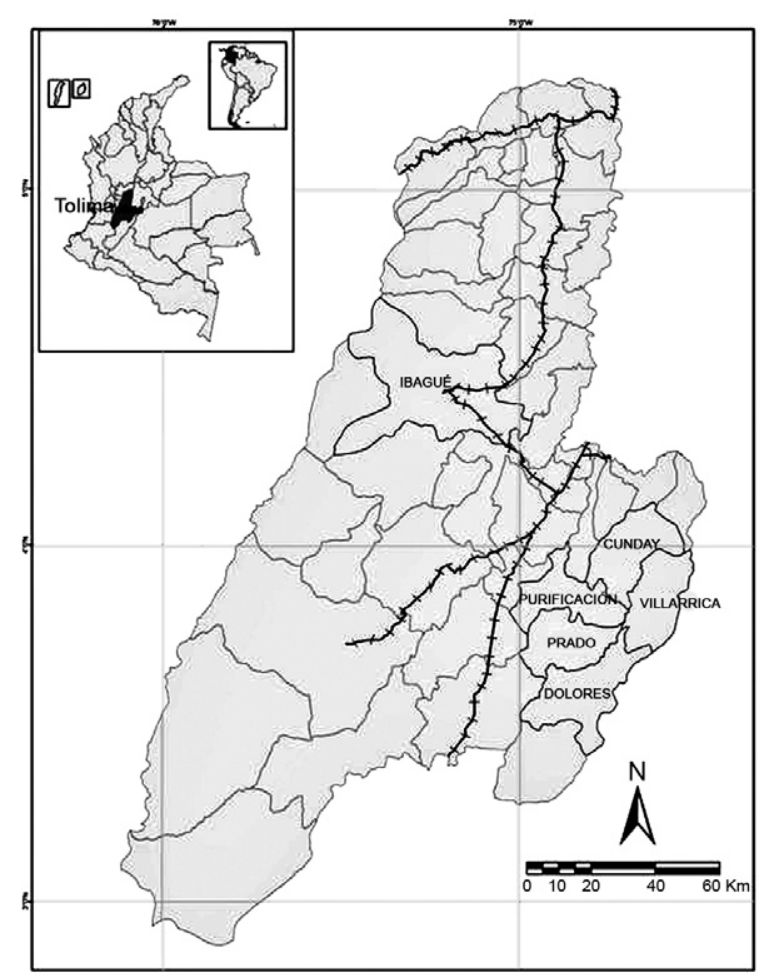

Fig. 1: location of the study area, foci of Cunday-Villarica, Department of Tolima, Colombia. Map realised by Geógrafos del Valle. 
content with a larger pipette. Larvae of Anopheles were collected from 41 trees with 78 bromeliads and brought to the laboratory of the National University of Colombia for rearing to the adult stage. IV instar larvae were individualised and larval and pupal skins were obtained to achieve 37 full entomological series. Male genitalia and larval and pupal skins were mounted.

Morphological analysis - Diagnostic characters of females, IV instar larvae and male genitalia were studied based on the descriptions and morphological keys of Zavortink (1973) and Harrison et al. (2012).

Molecular methods - Forty-four specimens were processed as belonging to An. (Kerteszia) sp. and their DNA was extracted using the DNeasy Blood \& Tissue Kit (QIAgen ${ }^{\circledR}$, USA). The rDNA ITS2 region was amplified using the primers of Collins and Paskewitz (1996) and the polymerase chain reaction (PCR) conditions described by Linton et al. (2001). A portion (710 bp) of the barcoding region of COI (mDNA) was amplified using the primers designed by Folmer et al. (1994) and the PCR conditions described by Ruiz et al. (2010). The products were visualised on $1 \%$ agarose gel containing $0.5 \mathrm{mg} /$ $\mathrm{mL}$ of ethidium bromide. The PCR product was purified using ExoSAP-IT ${ }^{\circledR}$ (USB Corporation, USA).

Sequencing reactions were carried out in both directions using the Big Dye terminator $\mathrm{Kit}^{\mathbb{B}}$ (PE Applied Biosystems, England) on an ABI 3730 automated sequencer (PE Applied Biosystems). The sequences were edited with Sequencher ${ }^{\mathrm{TM}} 4.10 .1$ (Gene Codes Corporation, USA) and aligned manually and translated to amino acids in MacClade v.4.06 (Maddison \& Maddison 2003). Sequence similarities were compared with those available in GenBank using Basic Local Alignment Search Tool (BLAST) (ncbi.nlm.nih.gov/genbank/) and sequence statistics were calculated in MEGA v.5 (Tamura et al. 2011).

Ethics - This study was approved by the Ethical Committee of the Faculty of Medicine of the National University of Colombia, according to consecutive number E-31, on 26 June 2008.

\section{RESULTS}

Table shows the sampling locations in the study area and the sampling dates. A total of 1,737 anopheline females were analysed morphologically. Of these females, 1,596 were collected landing on humans in the period between 2009-2012 and 141 females were sampled between 1981-1983.

The first morphological analysis was conducted using the dichotomous keys of Zavortink (1973). As a result of this analysis, $76 \%(1,218)$ of the collected specimens corresponded to either An. lepidotus or An. pholidotus and 24\% (378) were in agreement with an identification of An. boliviensis. According to Zavortink's key (1973), the only difference existing between An. lepidotus and An. pholidotus is restricted to the size of the scales on the female abdomen. As a result, it is difficult to determine which of these two species is present in the study region using this morphological key. Considering this issue, a second morphological analysis was made using the dichotomous key proposed by Harrison et al. (2012). This key can separate An. lepidotus females from $A n$. pholidotus females according the following diagnostic features: (i) females with white scales on the proboscis, pedicel and palpomere I; hindtarsomeres I and 2 without apical pale band (from dorsal view) are classified as An. lepidotus and (ii) females without white scales on the proboscis, pedicel and palpomere I; hindtarsomeres I and 2 with narrow apical pale band (from dorsal view) are classified as An. pholidotus.

All females captured in Tolima showed morphological characteristics that were similar to those assigned to An. pholidotus. Additionally, the females of An. pholidotus exhibited numerous scales with variable widths on tergites and sternites II-VII, hindtarsal segment 2 with white bands in the apical pale band between 0.1-0.2 as the total length of the tarsomere, mesanepimeron with large curved patch of scales extending from higher bristles to below the middle of the segment, scales in the proximal tergites and scales of the distal tergites forming transverse apical bands (Fig. 2).

IV instar larvae - Twenty-eight micro-preparations of IV instar larvae were analysed. The larvae showed a characteristic coloration pattern in the dorsal area of the thorax and abdominal segments I and V (Fig. 3). The morphological characteristics of this instar coincided with those described by Zavortink (1973) for An. pholidotus. Setae 5-7-C simple, not plumose, moderately long, characteristics of the Kerteszia subgenus; setae 6-VI moderately long, always different to 6-III-V, setae 1-IIIVII small palmate with pointed leaflets, pecten teeth of similar size all long, with marginal spinules extended to the apex, setae 1-I not palmate, setae 4-C always less developed than 2-C, setae 1-VII filiform, not palmate.

According to Zavortink (1973), two morphological characteristics help differentiate An. lepidotus from $A n$. pholidotus in this larval stage: An. pholidotus shows a setae 3-C that is moderately developed and approximately $1 / 2$ the length of 2-C, while An. lepidotus shows a setae $3-\mathrm{C}$ that is short and thick, fusiform and less than $1 / 2$ the length of 2-C. The 28 specimens analysed in this study presented an average length of $0.19 \pm 0.01 \mathrm{~mm}$ for the setae 2-C and of $0.11 \pm 0.004 \mathrm{~mm}$ for the setae 3-C, showing that in all cases the length of the setae 3-C is more than half the length of the setae 2-C (Fig. 4A), which corresponds to An. pholidotus. The clypeal index was $0.98 \pm 0.15$. The second discriminatory character is the setae 11-P, which is well developed for An. pholidotus. A very short 11-P would correspond to An. lepidotus. All larvae tested showed the setae 11-P to be well developed (length $=0.32 \pm 0.03 \mathrm{~mm}$ ), with an average of $66.7 \%$ of the length of the 12-P setae $(0.48 \pm 0.03 \mathrm{~mm})$ (Fig. 4B).

Some diagnostic characteristics described by Harrison et al. (2012) showed that for An. lepidotus, the seta $3-\mathrm{C}$ is very thick, short and usually sharply pointed; however, seta 11-P is always very short and setae VI is stout and long. As mentioned above, the specimens analysed in this investigation showed characteristics that do not match those described for An. lepidotus. 
TABLE

Sampling localities of Cunday-Villarrica focus in the Department of Tolima, Colombia

\begin{tabular}{|c|c|c|c|}
\hline Municipality & Coordinates & Locality & Sampling period \\
\hline Cunday & $\begin{array}{c}04^{\circ} 47^{\prime} 59.1^{\prime \prime} \mathrm{N} \\
74^{\circ} 34^{\prime} 50.21^{\prime \prime} \mathrm{W}\end{array}$ & San Francisco & February 2009 \\
\hline Icononzo & $\begin{array}{l}04^{\circ} 51^{\prime} 02.1^{\prime \prime} \mathrm{N} \\
74^{\circ} 09^{\prime} 003 ” \mathrm{~W}\end{array}$ & $\begin{array}{c}\text { Valencia } \\
\text { Cuatimbal } \\
\text { Alto Icononzo }\end{array}$ & $\begin{array}{c}\text { November } 1981 \\
\text { October } 1982 \\
\text { October } 1982\end{array}$ \\
\hline Villarrica & $\begin{array}{l}03^{\circ} 52^{\prime} 03.4^{\prime \prime} \mathrm{N} \\
74^{\circ} 39^{\prime} 09.8^{\prime \prime} \mathrm{W}\end{array}$ & $\begin{array}{c}\text { Puerto Lleras } \\
\text { Totumal } \\
\text { Guanacas } \\
\text { Rio Lindo } \\
\text { Rio Lindo } \\
\text { Rio Lindo } \\
\text { Rio Lindo }\end{array}$ & $\begin{array}{c}\text { February 1981-December } 1982 \\
\text { June 1981-February } 1983 \\
\text { June 1982-February } 1983 \\
\text { February-November } 2009 \\
\text { August } 2010 \\
\text { August-September } 2011 \\
\text { April-July } 2012\end{array}$ \\
\hline Purificación & $\begin{array}{c}03^{\circ} 51^{\prime} 58.11^{\prime \prime N} \\
74^{\circ} 55^{\prime} 59.83^{\prime \prime} \mathrm{W}\end{array}$ & Villa Esperanza & May 2009 \\
\hline Prado & $\begin{array}{l}03^{\circ} 45^{\prime} 04.15^{\prime \prime} \mathrm{N} \\
74^{\circ} 49^{\prime} 55.9^{\prime \prime} \mathrm{W}\end{array}$ & El Cruce & May 2009 \\
\hline
\end{tabular}

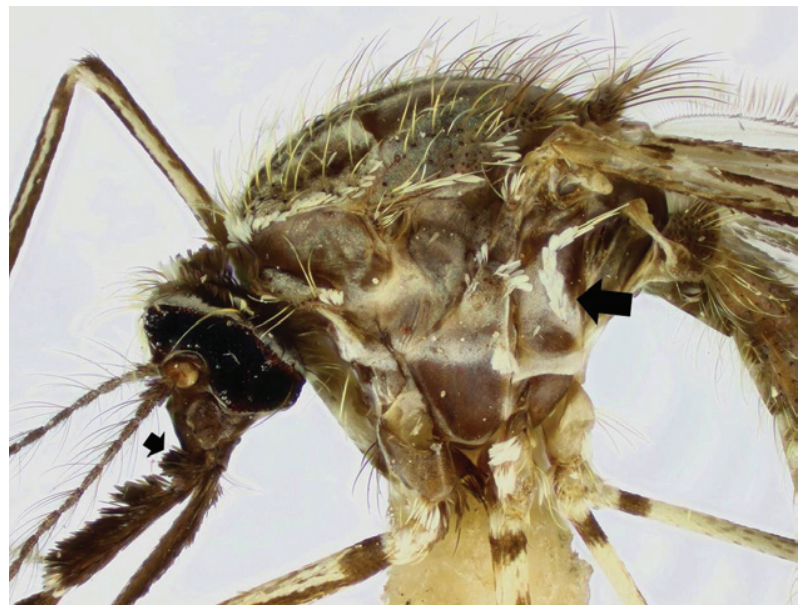

Fig. 2: lateral view of female of Anopheles pholidotus. Right arrow shows mesepimeron with one large and curved patch of scales that extends ventrally from upper setae. Left arrow shows palpomere 1 without scales.

Male genitalia - Twenty-five micro-preparations of male genitalia from a series were analysed. The morphological characteristics for this structure coincided with those described by Zavortink (1973) and González and Carrejo (2009) for An. pholidotus, but not for An. lepidotus. The specific characteristics were gonocoxite with long and sinusoid parabasal setae, always greater than $1 / 3$ the total length of gonocoxite; one internal seta flattened at the apex and two accessory ones located apically, an aedeagus without leaflets (Fig. 5A), a lateral expansion of the ventral lobe of claspette, moderately spiculose except laterally and rounded (Fig. 5B, C). The 25 male genitalia analysed in this study showed a lateral expansion of the ventral lobe of claspette corresponding

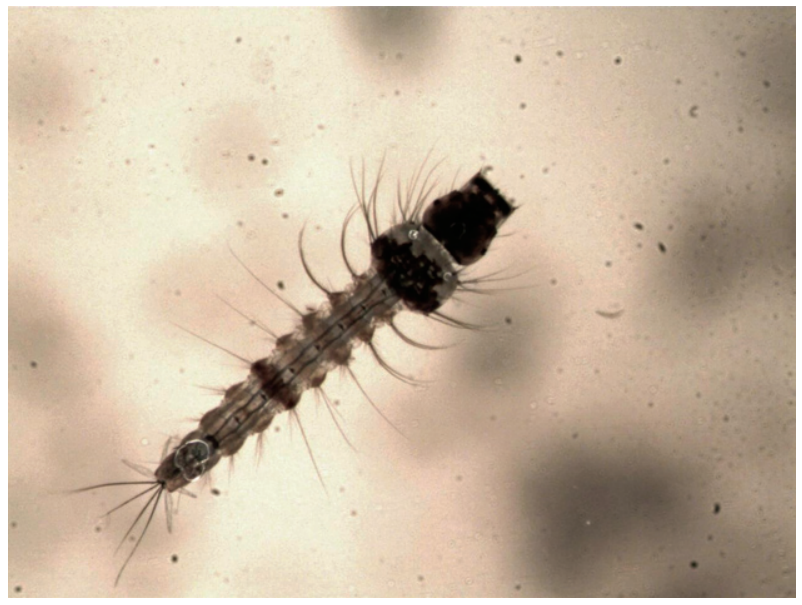

Fig. 3: general view that shows the dorsal coloration pattern of larvae IV instar of Anopheles pholidotus.

to the typical shape of An. pholidotus described by Zavortink (1973) and González and Carrejo (2009).

DNA sequences - Ninety-five specimens were sequenced with the molecular markers COI and ITS2. Only one haplotype was observed for each marker, confirming the lack of an intraspecific variation in all of the individuals analysed.

The COI barcode region (658 bp) consisted of a single open reading frame, discarding the presence of pseudogenes. Its nucleotide frequencies (\%) were A: $27.7 \%$, T: 40.9\%, G: $15.5 \%$ and C: $16 \%$ (Fig. 6). The ITS2 fragment showed no length variability (546 bp) and its nucleotide frequencies were A: $26.4 \%$, T: $19.4 \%$, G: $26.7 \%$ and C: $27.5 \%$ (Fig. 7). 

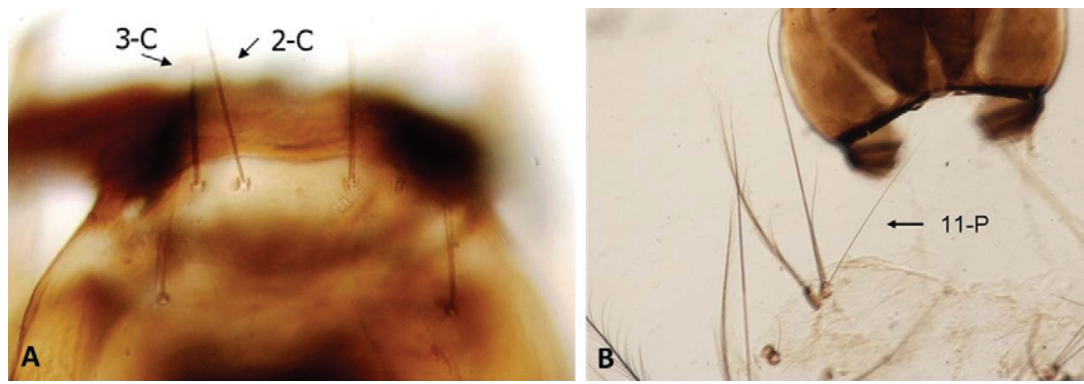

Fig. 4: larvae IV instar of Anopheles pholidotus (400X). A: head. Clipeal setaes (2-C and 3-C); B: prothorax. Setae 11-P.
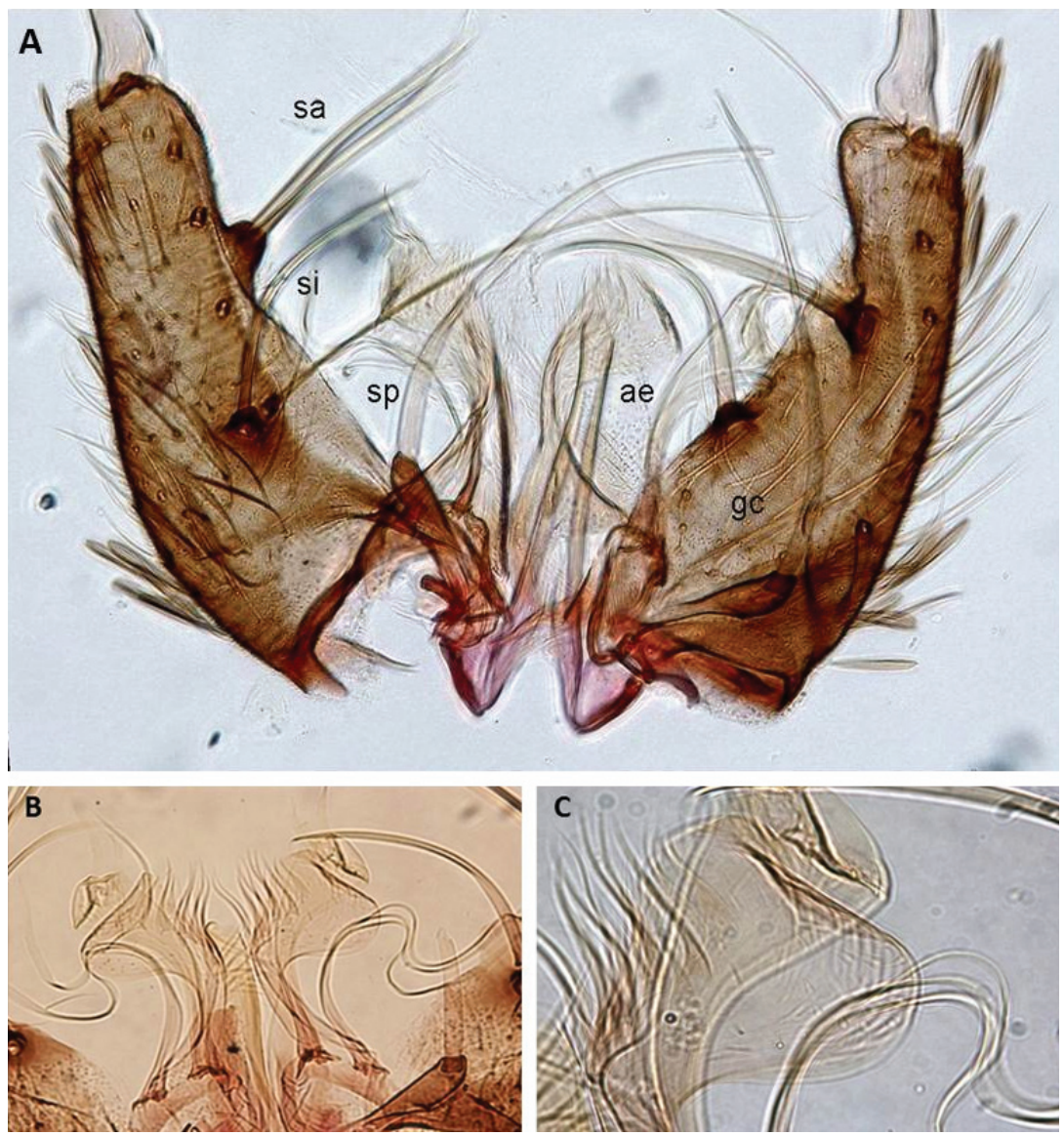

Fig. 5: male genitalia of Anopheles pholidotus. A: general view (200X) (ae: aedeagus; gc: gonocoxite; sa: accesory setaes; si: internal setae; sp: parabasal setae); B: view of lateral expansion of ventral lobe of claspette (400X); C: ventral lobe of claspette expanded showing the characteristic form of An. pholidotus (1,000X).

The sequences of ITS2 were submitted to BLAST, where high significant homology $(100 \%)$ was found with the sequences of An. pholidotus (from Táchira, Venezuela) (accessions JN967769.1, JN967768.1) published by Harrison et al. (2012).

$\mathrm{COI}$ sequences, compared with sequences in the Barcode of Life Data Systems (Bold Systems) (boldsystems. org), showed $100 \%$ similarity with An. pholidotus.

\section{DISCUSSION}

Until the study published by Harrison et al. (2012), the only morphological feature that had been proposed to differentiate females of An. pholidotus from An. lepi- dotus were, according to Zavortink (1973), the size of the scales on proximal tergites. Those were described as moderately wide or broad for An. lepidotus and predominantly narrow to moderately wide for An. pholidotus, with those differences being rather subjective. This taxonomic characteristic is vague and difficult to interpret, so it would be inaccurate to separate female adults of these two species based only on these characteristics. Therefore, it was essential to analyse other morphological structures and associated stages, such as male genitalia and to use the chaetotaxy of IV instar larvae. Even so, genitalia analysis presents a "weak spot" or a "bottle neck" effect in the separation of these two species be- 
GGTCAACAAA TCATAAAGAT ATTGGTACTT TATATTTTAT TTTTGGAGCT TGAGCTGGAA 60 TAGTTGGAAC TTCTTTAAGA ATTTTAGTTC GAGCTGAATT AGGTCATCCT GGTGCTTTTA 120 TTGGAGATGA CCAAATTTAT AATGTTATTG TAACTGCTCA TGCTTTTATC ATAATTTTTT 180

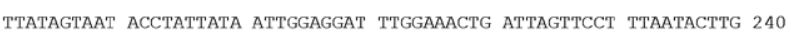
GAGCTCCTGA TATAGCTTTC CCTCGAATAa ATAATATAAg ATtTTGAATA CTTCCTCCTT 300 CTTTAACTCT TTTAATTTCA AgAagtatAG TAGAAAATGG AGCTGGAACA GGTTGAACTG 360 TTtATCCTCC TCTATCATCT GGAATtgCCC ACGCCGGAGC TTCAGTAGAT TTAGCTATtT 420 TTTCTTtACA TTTAGCAGGT ATTTCTTCTA TTTTAGGAGC AGTAAATTTT ATTACCACAG 480 TAATTAATAT ACGATCTCCA GGAATTACTT TAGATCGAAT ACCATTATTT GTTTGATCAG 540 TTGTAATTAC TGCAATTTA TTACTTTTAT CTTTACCAGT TTTAGCTGGA GCTATTACTA 600 TACTTTTAAC TGACCGAAT CTTAATACTT CTTTTTTTGA CCCCGCTGGA GGAGGAGACC 660 CTATTTTATA CCAACATTTA TTTTGATTTT TTGGTCACCC TGAATTTAG 710

Fig. 6: cytochrome oxidase I sequence of Anopheles pholidotus from Villarrica, Department of Tolima, Colombia using the Folmer et al. (1994) primer ( $\mathrm{n}=10,710 \mathrm{bp})$. Only one haplotype was found. Primers sequences are underlined and in bold.

ATCACTCGGC TCGTGGATCG ATGAAGACCG CAGCTAAATG CGCGTCAGAA TGTGAACTGC 60 AgGACACATG AaCACCGATA CGTTGAACGC ATATtgCGCA tCGCACGACA CAgtgCGATG 120 TACACATTTT TGAGTGCCCA TCCTCACCGC ATAGCCAACT ATCGGGGAAC GCGCCATGCG 180 CTTCCCGATG CATTATGATG CGTTGCCCGG CCCCGGCTGG TCAATCATTG AAAGACTGTG 240 TGCGTAGGAG GGGCCGACCG GAGCGTCCGC TTTCGCGAGT GTCTTCCGTC ACGGCTGAGC 300 CACCTTACGA CTCTCACCAA CACGAGATAC GATGGTGCAG AACAAATCCA TATCGAACGA 360

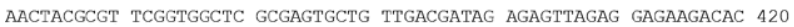
AGCAGGCAGA GAGACCGCGC ATATCGCTGG AGAGCGCGAA CGCACCGGCC GGCGTTACCA 480 CAACATGACA CACGAAATCT ATAGTGGGCC TCAAATAATG TGTGACTACC CCCTAAATTT 540 AAGCAT 546

Fig. 7: internal transcribed spacer sequence of Anopheles pholidotus from Villarrica, Department of Tolima, Colombia using the Collins and Paskewitz (1996) primers $(\mathrm{n}=10,546 \mathrm{bp})$. Only one haplotype was found. Primers sequences are underlined and in bold.

cause in Zavortink's key (1973), the presence or absence of scales in VII tergite in the abdomen of adults must be verified at one point, which is an external feature of the genitalia. Thus, the dichotomous key of Harrison et al. (2012) is useful for separating females of both species.

As mentioned above, for several years, there was evidence of the presence of An. pholidotus rather than $A n$. lepidotus in the Cunday-Villarrica focal region (González \& Carrejo 2009). Even just three years after the report of Quiñones et al. (1984), the presence of An. lepidotus in that zone was questioned (Harrison et al. 2012).

The limited availability of specimens collected from the area for morphological analysis, the scarcity of associated stages, the poor condition of some of the samples and the difficulty of accessing the area to collect new biological information most likely delayed the opportunity to solve this problem by three decades.

The collections of mosquitoes for this study, which occurred between February 2009-October 2011, provided updated information about the species of anophelines in these focal areas. According to the morphological features of females, the larvae chaetotaxy, the male genitalia presented in the specimens of Cunday-Villarrica malaria focal area in Tolima and the analysis of the $C O I$ and ITS2 sequences, An. pholidotus was the most common species found and was most likely misidentified as $A n$. lepidotus in the previous report (Quiñones et al. 1984).

It is now possible to differentiate females of An. pholidotus from An. lepidotus using the dichotomous key. The fact that females of An. lepidotus were not found by analysing 1,737 individual mosquitoes captured indicates that the species that was previously reported as the vector of malaria in the area since 1984 (Quiñones et al. 1984) was An. pholidotus and not An. lepidotus.

The sequences obtained in this investigation, both COI and ITS2, showed that the tested specimens correspond to An. pholidotus, thus confirming the results of the morphology analysis. Sequences from three localities of Tolima exhibit no intraspecific variability, showing that An. pholidotus is present in the study area as a single species, although this may not be true in other parts of the country due to the high altitude of certain mountain ranges. Olano et al. (2001) and González and Carrejo (2009) provided records of supposed "An. lepidotus" in different departments of the country. For example, we have identified, by morphology, three females from Valle del Cauca (PNN Farallones: Cali, Pance, VI6-1984, 1,500 m) as An. pholidotus. This result indicates that there is a possibility that An. pholidotus has a wider distribution than previously thought and that many of the specimens identified as An. lepidotus may correspond to An. pholidotus. Moreover, the sequences mentioned above show 100\% homology with sequences of $A n$. pholidotus from Táchira, Venezuela, recorded in GenBank by Harrison et al. (2012). As a result, it is important to determine whether this homology is generalised to all countries where An. pholidotus is present.

Harrison et al. (2012) inadvertently forgot to include the precise location of the record for An. pholidotus in Costa Rica. A single female in the mosquito collection located at the NMNH at the Smithsonian Institution was collected resting on the wall of a highway tunnel. The collection data record was as follows: Costa Rica: Cartago, Res. Tapanti; unnamed tribs., Ca. 9 Km (road NW tunnel, 9.72 N, 83.78 W, 8.9.vi.1988, elv. 1,400 m, CM \& OS Flint, Molzenthal).

One of the key aspects for optimising control measures is an appropriate taxonomic determination of the species that are present and those that are responsible for transmission. Taxonomic studies in Kerteszia species are relevant because the distribution of this subgenus along the continent is still poorly known, mainly due to the lack of research studies. Furthermore, the association of these species with areas where bromeliads are normally present means that environmental changes and human activity may restrict the distribution for some species in the subgenus (Marrelli et al. 2007) However, for other species, the same factors may stimulate the proliferation of breeding sites and possibly extend their geographical distribution (Solarte et al. 1994).

\section{REFERENCES}

Benítez JA, Rodríguez A, Sojo M, Lobo H, Villegas C, Oviedo L, Brown E 2004. Descripción de un brote epidémico de malaria de altura en un área originalmente sin malaria del estado de Trujillo, Venezuela. Boletín de Malariología y Salud Ambiental 44: 93-99. 
Carvajal H, de Herrera MA, Quintero J, Alzate A, Herrera S 1989. Anopheles neivai: a vector of malaria in the Pacific low lands of Colombia. Trans R Soc Trop Med Hyg 83: 609.

Collins FH, Paskewitz SM 1996. A review of the use of ribosomal DNA (rDNA) to differentiate among cryptic Anopheles species. Insect Mol Biol 5: 1-9.

Collucci E, Sallum MAM 2003. Phylogenetic analysis of the subgenus Kerteszia of Anopheles (Diptera: Culicidae: Anophelinae) based on morphological characters. Insect Syst Evol 34: 361-372.

Cova-García P 1961. Notas sobre los anofelinos de Venezuela y su identificación, 2nd ed., Grafos, Caracas, 213 pp.

de Carvalho-Pinto CJ, Lourenço-de-Oliveira R 2004. Isoenzimatic analysis of four Anopheles (Kerteszia) cruzii (Diptera: Culicidae) populations of Brazil. Mem Inst Oswaldo Cruz 99: 471-475.

Escobar J, González R, Quiñones ML, Wilkerson RC, Harrison B 2010. Presence of Anopheles (Kerteszia) pholidotus in a malaria focus in Colombia. In G Clark, Y Rubio-Palis, Mosquito vector biology and control in Latin America - A 20th symposium. J Am Mosq Control Assoc 26: 306-320.

Folmer O, Black M, Hoeh W, Lutz R, Vrijenhoek R 1994. DNA primers for amplification of mitochondrial cytochrome $\mathrm{c}$ oxidase subunit I from diverse metazoan invertebrates. Mol Mar Biol Biotechnol 3: 294-299.

Forattini OP, Kakitani I, dos Santos RC, Ueno HM, Kobayashi KM 1999. Role of Anopheles (Kerteszia) bellator as malaria vector in southeastern Brazil (Diptera: Culicidae). Mem Inst Oswaldo Cruz 94: 715-718.

González R, Carrejo N 2009. Introducción al estudio taxonómico de Anopheles de Colombia. Claves y notas de distribución, 2nd ed., Universidad del Valle, Cali, 248 pp.

Gutierrez LA, Nelson N, Jaramillo LM, Muskus C, Luckhart S, Conn JE, Correa M 2008. Natural infectivity of Anopheles species from the Pacific and Atlantic Regions of Colombia. Acta Trop 107: 99-105.

Harbach RE, Navarro JC 1996. A new species of Anopheles, subgenus Kerteszia (Diptera: Culicidae) from Venezuela. Ent Scand 27: 207-216.

Harrison BA, Ruíz-López F, Calderón G, Savage HM, Pecor JE, Wilkerson RC 2012. Anopheles (Kerteszia) lepidotus (Diptera: Culicidae), not the malaria vector we thought it was: revised male and female morphology; larva, pupa and male genitalia characters and molecular verification. Zootaxa 3218: 1-17.

Komp WHW 1937. The species of the subgenus Kerteszia of Anopheles. Ann Entomol Soc Am 30: 492-529.

Linton Y-M, Harbach RE, Anthony TG, Chang MS, Asmad M 2001. Morphological and molecular identity of Anopheles (Cellia) sundaicus (Diptera: Culicidae), the nominotypical member of a malaria vector species complex in Southeast Asia. Syst Entomol 26: 357-366.
Maddison DR, Maddison WR 2003. MacClade v.4.06: analysis of phylogeny and character evolution, Sinauer Associates, Sunderland, MA.

Marrelli MT, Malafronte RS, Sallum MAM, Natal D 2007. Kerteszia subgenus of Anopheles associated with the Brazilian Atlantic rainforest: current knowledge and future challenges. Malar J 6: 127.

Montoya J, González R, Palma G, Solarte Y, Olano V 1994. Malaria. In BL Travi, J Montoya-Lerma, Centro Internacional de Entrenamiento e investigaciones Médicas (eds.), Manual de entomología médica para investigadores de América Latina, CIDEIM, Cali, p. 163-209.

Montoya-Lerma J, Solarte YA, Giraldo-Calderón GI, Quiñones ML, Ruiz-López F, Wilkerson RC, González R 2011. Malaria vector species in Colombia - A review. Mem Inst Oswaldo Cruz 106 (Suppl. I): 223-238.

Olano V, Brochero H, Sáenz R, Quiñones M, Molina J 2001. Mapas preliminares de la distribución de Anopheles vectores de malaria en Colombia. Biomédica 21: 402-403.

Quiñones M, Suárez M, Rodríguez A, Fleming G, Galvis L 1984. Comportamiento de Anopheles (Kerteszia) lepidotus Zavortink, 1973, y su incriminación como posible vector de malaria en el Departamento del Tolima, Colombia. Biomédica 4: 5-13.

Rubio-Palis Y, Zimmerman RH 1997. Ecoregional classification of malaria vectors in the Neotropics. J Med Entomol 34: 499-510.

Ruiz F, Linton Y-M, Ponsonby DJ, Conn JE, Herrera M, Quiñones ML, Vélez ID, Wilkerson RC 2010. Molecular comparison of topotypic specimens confirms Anopheles (Nyssorhynchus) dunhami Causey (Diptera: Culicidae) in the Colombian Amazon. Mem Inst Oswaldo Cruz 105: 899-903.

Sallum MAM, Schultz TR, Foster PG, Wirtz RA, Wilkerson RC 2002. Phylogeny of Anophelinae (Diptera: Culicidae) based on nuclear ribosomal and mitochondrial DNA sequences. Syst Entomol 27: 361-381.

Solarte Y, González R, Hurtado JC, Alzate A 1994. Influencia de la vegetación en la presencia, distribución y abundancia de criaderos de tres especies de Anopheles (DIP.: Culicidae) en la parte baja del río Naya, costa pacífica de Colombia. Bol Mus Ent Univ Valle 2: 55-71.

Tamura K, Peterson D, Peterson N, Stecher G, Nei M, Kumar S 2011. MEGA 5: molecular evolutionary genetics analysis using maximum likelihood, evolutionary distance and maximum parsimony methods. Mol Biol Evol 28: 2731-2739.

Ueno HM, Forattini OP, Kakitani I 2007. Vertical and seasonal distribution of Anopheles (Kerteszia) in Ilha Comprida, southeastern Brazil. Rev Saude Publica 41: 269-275.

Zavortink TJ 1973. Mosquitoes studies (Diptera: Culicidae). XXIX A review of the subgenus Kerteszia of Anopheles. Contrib Amer Ent Inst 9: 1-59. 